\title{
O MARINHEIRO: "NAVEGAR É PRECISO, VIVER NÃO É PRECISO"*
}

\author{
O MARINHEIRO: "SAILING IS NECESSARY, LIVING IS NOT NECESSARY" \\ http://dx.doi.org/10.11606/issn.2175-3180.v12i23p156-165
}

Francisco Maciel Silveira ${ }^{\mathrm{I}}$

\section{RESUMO}

O Marinheiro (1913) antecipa motivos que Fernando Pessoa desenvolverá na obra ortônima e heterônima - o desdobramento do ser; a incapacidade de sentir sem estar a pensar-se sentir; o mistério do ser o médium de si mesmo, ser só o que tinha possibilidades. A peça corresponde ao primeiro grande passo no sentido da despersonalização máxima a que objetivava sua obra: a realização da heteronímia. Este artigo, portanto, examinará a dissociação aparência/essência que se desdobra em dois espaços, o do palco e o da palavra poética, para concluirmos que $O$ Marinheiro acaba sendo o verdadeiro manifesto do Orpheu, na medida em que concretiza o encantamento órfico da palavra poética, impondo-a como realidade única e absoluta espaço inteligível gerador do plano sensível, essa sombra enganosa da verdadeira realidade. Demiurgo platônico, o marinheiro pessoano sonha as sombras de nossa realidade. Enfim, veladoras da realidade, não passamos de meras sombras e reminiscências - simulacros da verdadeira realidade de que nos exilamos.

\section{PALAVRAS-CHAVE}

Fernando Pessoa; Heteronímia; Drama estático; Simbolismo.

\section{ABSTRACT}

O marinheiro (1913) anticipates motifs that Fernando Pessoa would go on to develop in both his orthonymous and heteronymous oeuvre - the unfolding of the self; the impossibility of feeling without thinking of feeling; the mystery of being the medium of oneself, and being only what is possible. The play constitutes the first major step towards the maximum depersonalization which is his work's objective: the realization of heteronymy. This paper will therefore examine the dissociation between appearance and essence, which occurs in two spaces - the space of the stage and the space of the poetic word concluding that $\mathrm{O}$ marinheiro is the true manifesto of Orpheu, inasmuch as it materializes the orphic enchantment of the poetic word, imposing it as the only absolute reality an intelligible space which creates the perceptible plane, that deceptive shadow of true reality. The Pessoa's seaman is a Platonic demiurge who dreams the shadows of our reality. Ultimately, as watchers of reality, we are no more than mere shadows and reminiscences - simulacra of the true reality from which we have exiled ourselves.

\section{KEYWORDS}

Fernando Pessoa; Heteronymy; Static drama; Symbolism.

\footnotetext{
* Versão preliminar deste texto foi apresentada em comunicação oral no Colóquio Internacional 100 anos de Orpheu, em 2015.

I Universidade de São Paulo, São Paulo, Brasil.
} 
Poema dramático, escrito entre os dias 11 e 12 de outubro de 1913, e publicado no primeiro número da revista Orpheu (jan.-mar./1915), portanto antes da gênese da heteronímia que ocorre à volta de 1914, O Marinheiro antecipa motivos que Fernando Pessoa desenvolverá na obra ortônima e heterônima - o desdobramento do ser (ver-se a ver/ouvir-se a ouvir $\rightarrow 2^{\underline{a}}$ veladora, PESSOA, 1976, p. 46-47); a incapacidade de sentir sem estar a pensar-se sentir $\rightarrow 1^{\text {a }}$ veladora (PESSOA, 1976, p. 46); o mistério do ser (PESSOA, 1976, p. 37, 40, 47) o médium de si mesmo $\rightarrow 2^{\underline{a}}$ veladora (PESSOA, 1976, p. 41), ser só o que tinha possibilidades $\rightarrow 2^{\text {a }}$ veladora (PESSOA, 1976, p. 44); a realidade desdobrada nos planos sensível e inteligível.

O Marinheiro corresponde ao primeiro grande passo no sentido da despersonalização máxima a que objetivava sua obra: a realização da heteronímia (PESSOA, 1976, p. 275). Esse primeiro grande passo representado pelo drama $O$ Marinheiro é o Sensacionismo a três dimensões, suprema fase do Sensacionismo, que correspondia a sentir por imagens, dando forma concreta às sensações, em busca da "objectivização", ou seja, uma interpretação objetivada duma impressão subjetiva.

Em O Marinheiro, as sensações, os estados de alma encontram-se relativamente concretizados em seres, mas estes seres (as veladoras) ainda não alcançaram a individuação de personagens, nem tampouco apresentam estilo próprio, com sentimentos diferentes e até opostos aos da pessoa do criador. $\mathrm{O}$ que não impede que parte da crítica acadêmica incorra no equívoco de procurar encontrar nas Veladoras os espectros seminais de Reis, Campos e Caeiro.

O objetivo de Fernando Pessoa era criar drama em gente, levar a poesia lírica "até à poesia dramática, sem, todavia, se lhe dar a forma de drama, nem explícita nem implicitamente" (PESSOA, 1976, p. 87). O Marinheiro seria, pois, um ensaio em direção ao seu objetivo de despersonalização.

2.

Como desejava uma poesia dramática sem forma explícita ou implícita de drama, O Marinheiro começa por questionar a fôrma explícita 
drama. Assim, terá a aparência de uma peça teatral, a forma de uma peça teatral, mas é um drama que se recusa a ser drama, ao denominar-se "drama estático em um quadro". Num manuscrito de possivelmente 1914, Pessoa dá o seu conceito de teatro estático:

Chamo teatro estático àquele cujo enredo dramático não constitui ação - isto é, onde as figuras não só não agem, porque não se deslocam nem dialogam sobre deslocarem-se, mas nem sequer têm sentidos capazes de produzir uma ação; onde não há conflito nem perfeito enredo. Dirse-á que isto não é teatro. Creio que o é porque creio que o teatro tende a teatro meramente lírico e que o enredo do teatro é, não a ação nem a progressão e consequência da ação - mas, mais abrangentemente, a revelação das almas através das palavras trocadas e a criação de situações [...] Pode haver revelação de almas sem ação, e pode haver criação de situações de inércia, momentos de alma sem janelas ou portas para a realidade. (PESSOA, 1976, p.283).

Se considerarmos que o drama, no teatro, é essencialmente movimento e ação, já que é a progressão de um conflito, a concepção de drama estático pessoano nega a essência do próprio drama.

3.

Desse ângulo, sua concepção de teatro estático, concretizado em $O$ Marinheiro, aproxima-o da estética teatral simbolista:

a) nega à realidade material e histórica todo e qualquer valor em si mesma, donde encastelar-se fora do tempo (que século?), fora do espaço ("um quarto que é sem dúvida num castelo antigo"), quarto circular (uma torre de marfim?), com "uma única janela, alta e estreita", por onde "só se vê, entre dois montes longínquos, um pequeno espaço de mar.");

b) atmosfera misteriosa, vaga, entre realidade e sonho, criada pelo jogo luz/treva, iluminação imprecisa de quatro tochas e "um vago resto de lua", imergindo tudo na imprecisão que se nega a recortar espaço e seres;

c) recusa da ação, já que suas veladoras não entram em conflito, por meio do diálogo, simplesmente há a revelação de almas nas "palavras trocadas"; 
d) inexistência de caracteres individuados: três vozes que se desdobram a desenvolver uma ideia, incapazes de se destacarem nitidamente enquanto seres (com corpo, história e passado);

e) discurso poético, voluntariamente refratário ao discurso cotidiano;

f) concepção de teatro como "revelação de almas" (que tenderia a solilóquios longos e analíticos), personagens como encarnações ou meros suportes de ideias que o drama propõe ilustrar.

4.

Drama estático cuja fôrma teatral nega a essência teatral, $O$ Marinheiro, enquanto texto, é um ser que apresenta uma dissociação entre aparência e essência: dissociação entre o que os nossos sentidos apreendem (rubricas, falas, personagens situadas num cenário a lembrar-nos, em sua aparência, a fôrma teatral) e o que repousa para além dos sentidos - a essência. Estamos, pois, diante de uma dupla realidade, de matiz platônica: uma sensível e uma inteligível.

Esta dupla realidade está sugerida na rigorosa composição do cenário: a) composição geométrica (círculo, retângulo, triângulo) a apontar para realidades abstratas existentes num espaço virtual; $b$ ) signos retirados da concretude de uma realidade material (tocha, essa, caixão, quatro mulheres, janela etc.), mas cuja organização se faz no sentido de sugerir um significado para além do significado imediato deles: signos organizados de maneira conscientemente metafórica, encerrados num tempo e espaço (castelo antigo, sem relógio) que representam uma recusa do tempo cronológico e do espaço exterior.

Repúdio à realidade exterior e remissão para uma outra realidade é o que nos sugere o cenário. Já na rubrica percebe-se o apelo para ver (“Do quarto vê-se que é circular...") e imaginar ("À direita, quase em frente a quem imagina o quarto"), criando mais um conflito que se põe fora do palco, fora da ação. $\mathrm{O}$ apelar para nossa imaginação pode levar-nos a pensar que este drama estático, fiel à sua essência, não teria sido composto para ser encenado, visto, mas só lido e visto por meio da imaginação. Contudo, a rubrica é muito rigorosa e pormenorizada na composição do cenário - cenário que quer ser visto e não puramente imaginado.

Assim, o espectador vê o cenário - onde as figuras estão estáticas e onde não se desenrola nenhuma ação - e ouve a fala das veladoras, espaço 
que tem vida e onde as coisas acontecem. Delineiam-se, pois, dois espaços: o espaço do palco (quarto circular, num castelo antigo) e o espaço da palavra.

\section{5.}

O espaço do palco (quarto circular num castelo antigo) remete à realidade, isto é, pertence à vida, marcado pela morte (donzela no caixão) e pelo fluir do tempo (progressão da noite para o dia que há de despontar).

Nesse espaço ocorre a repulsa à realidade e à vida exterior:

a) O lá-fora do quarto circular é triste, feio: “Todo este país é muito triste...", "Só o mar das outras terras é que é belo..." $\rightarrow 2^{\underline{a}}$ Veladora (PESSOA, 1971, p.38).

b) Veladoras encasteladas, sem relógio, desterradas da vida: "Não rocemos pela vida nem a orla das nossas vestes." $\rightarrow 2^{\underline{a}}$ Veladora (PESSOA, 1971, p. 39).

c) Estaticidade, abulia, recusa a fazer quaisquer gestos, pois inúteis: "Agora eu gostaria de andar... Não o faço porque não vale a pena fazer nada, sobretudo o que se quer fazer..." $\rightarrow 2^{\underline{a}}$ Veladora (PESSOA, 1971, p. 41)

d) Não viver o aqui e agora: "Só viver é que faz mal..." $\rightarrow 2^{\text {a }}$ Veladora (PESSOA, 1971, p. 39).

Neste espaço considerado real por nossos falaciosos sentidos, as Veladoras entregam-se ao sortilégio do sonho, gerado pela palavra. Falar é um modo de esquecer-se, evadir-se: "É um modo tão falso de nos esquecermos..." $\rightarrow 1^{\text {a }}$ Veladora (PESSOA, 1971, p. 38).

O espaço da palavra ou do sonho é o espaço da aventura interior "De eterno e belo há apenas o sonho..." $\rightarrow$ 2a Veladora (PESSOA, 1971, p. $50)$, gerado pela palavra poética, a palavra das sereias, do encantamento órfico: a $3^{\mathrm{a}}$ Veladora diz a respeito da $2^{\mathrm{a}}$ que esta conhece as palavras que as sereias lhe ensinaram (PESSOA, 1976, p. 45). Trata-se da palavra que, deflagradora da realidade - ver diálogo da $1^{\underline{a}}$ e $2^{\underline{a}}$ Veladoras (PESSOA, 1976, p. 45) -, é capaz de dar vida e sentido às Veladoras, construindo-lhes um passado, uma infância, um espaço e tempo vicários e compensatórios. É nesse espaço da palavra que ocorre o sonho do Marinheiro.

Convém ressaltar que se percebem três momentos nesse espaço da Palavra: a) a palavra, sem assunto, testa sua potencialidade, à procura da objetivação e da objetificação; b) a palavra atinge sua plenitude, realizando- 
se no sonho do Marinheiro, ou seja a palavra transforma-se em realidade; c) transformada em realidade a palavra perde seu ser de Palavra, torna-se realidade palpável, desintegra-se, passando a existirem separadamente SE e SO - ver fala da 3a Veladora (PESSOA, 1976, p. 42) -, numa dissociação esquizofrênica que já sabe à heteronímia.

6.

Examinemos agora o sonho do Marinheiro. Insulado como as Veladoras, estático como elas, pois sonha deitado, realiza o desejo das Veladoras de criar novo espaço e novo tempo e outros seres com a matéria de sua alma. Assim,

a) Sonha Pátria que nunca teve: “... pôs-se a fazer ter sido sua uma outra pátria, uma outra espécie de país..." $\rightarrow 2^{\mathrm{a}}$ Veladora (PESSOA, 1976, p. 45);

b) Sonha sua nova terra natal; "Durante anos e anos, dia a dia o marinheiro erguia num sonho contínuo a sua nova terra natal..." $\rightarrow 2^{\mathrm{a}}$ Veladora (PESSOA, 1976, p. 46);

c) Construiu um novo passado: "E assim foi construindo o seu passado... Breve tinha outra vida anterior..." $\rightarrow 2^{2}$ Veladora (PESSOA, 1976, p. 47).

Um dia, o Marinheiro cansou-se de sonhar e quis recordar a pátria verdadeira, sua infância e passado verdadeiros, sua vida verdadeira, mas tinha perdido tudo: "Toda a sua vida tinha sido a sua vida que sonhara... E ele viu que não podia ser que outra vida tivesse existido... [...] E da vida que lhe parecia ter sonhado, tudo era real e tinha sido..." $\rightarrow 2^{\underline{a}}$ Veladora (PESSOA, 1976, p. 48).

Releva notar dois momentos no sonho do Marinheiro. No princípio, ele é uma coisa real a sonhar; no fim o sonho passa a ser real e ele irreal: "Veio um dia um barco, e passou por essa ilha, e não estava lá o marinheiro..." $\rightarrow 2^{\underline{a}}$ Veladora (PESSOA, 1976, p. 49).

O Marinheiro perdera seu ser, sua identidade, sua realidade.

7.

Num primeiro momento, o espaço do sonho que as veladoras querem habitar é um espaço compensatório, melhor que o espaço da vida e realidade lá fora: “De eterno e belo há apenas o sonho...” $\rightarrow 2^{\mathrm{a}}$ Veladora (PESSOA, 1976, 
p. 50); "Não valeria então a pena fecharmo-nos no sonho e esquecer a vida, para que a morte nos esquecesse?..." $\rightarrow 1^{\text {a }}$ Veladora (PESSOA, 1976, p. 50). Porém, de espaço compensatório e belo, o sonho do Marinheiro torna-se agente de terror, suscitando medo e horror nas Veladoras:

- 2 ${ }^{\text {a }}$ Veladora (PESSOA, 1976, p. 49-50): “Avançam para mim, por uma noite que não é esta, os passos de um horror que desconheço... Quem teria eu ido despertar com o sonho que vos contei?..."

- 3aㅡ Veladora (PESSOA, 1976, p. 53): “Minha irmã, não nos devíeis ter contado essa história. Agora estranho-me viva com mais horror."

-1믈 Veladora (PESSOA, 1976, p. 53): “Tudo isto, toda esta conversa, e esta noite - tudo isto devia ter acabado de repente, depois do horror que nos dissestes..."

- 1a Veladora (PESSOA, 1976, p. 54): "Para que foi que nos contastes a vossa história?"

Se a peça tivesse terminado logo após o sonho do Marinheiro, como, aliás, queria Álvaro de Campos:

\author{
Depois de doze minutos \\ Do seu drama o Marinheiro, \\ Em que os mais ágeis e astutos \\ Se sentem com sono e brutos, \\ E de sentido nem cheiro, \\ Diz uma das veladoras \\ Com langorosa magia:
}

De eterno e belo há apenas o sonho.

Por que estamos nós falando ainda?

Ora isso mesmo é que eu ia

Perguntar a essas senhoras... (PESSOA, 1969, p. 341, grifo nosso)

Se não tivesse progredido de espaço compensatório e belo para espaço de terror e medo, teríamos permanecido nas camadas do óbvio, a proclamar que de eterno e belo só o sonho. A originalidade está exatamente em mostrar como o Belo pode gerar o Terror, revelando quão perigosa é a aventura interior do sonho, quando passa a exigir foros de realidade. A mesma fala capaz de criar o sonho, prosseguindo na análise e dissecação de sua essência e natureza, esgota-lhe o sentido, reduzindo-o à inutilidade.

Por que o sonho do Marinheiro deixa de ser bom e belo para despertar o Horror? 
O sonho do Marinheiro traz a consciência de que a aventura interior do sonho vulnera a realidade, diluindo as fronteiras assentes entre o Real e o Irreal: "Não pensemos mais... Não tentemos seguir nesta aventura interior... Quem sabe o que está no fim dela?..." $\rightarrow 2^{\text {a }}$ Veladora (PESSOA, 1976, p. 50).

A ideia, a noção que as embalava de que "sem dúvida nada é inteiramente falso" $\rightarrow 2^{\text {a }}$ Veladora (PESSOA, 1976, p. 44), aguça-se após o sonho do Marinheiro:

- "Tudo o que acontece é inacreditável, tanto na ilha do marinheiro como neste mundo... [...] por que não será a única coisa real nisto tudo o marinheiro, e nós e tudo isto aqui apenas um sonho dele?..." $\rightarrow 2^{\underline{a}}$ Veladora (PESSOA, 1976, p. 51)

Ao que responde a 1ํㅡㄹ Veladora (PESSOA, 1976, p. 51): “Isso é tão estranho que deve ser verdade..."

Rompida a fronteira entre o Real e o Sonho, o Terror invade as veladoras:

a) $\mathrm{O}$ terror de não ser, transformadas em marionetes, articulando a ventriloquia do sonho do Marinheiro - "Quem é que eu estou sendo?... Quem é que está falando com a minha voz?..." $\rightarrow 1^{\underline{a}}$ Veladora (PESSOA, 1976, p. 54);

"Quem é a quinta pessoa neste quarto que estende o braço e nos interrompe sempre que vamos a sentir?..." $\rightarrow 2^{\underline{a}}$ Veladora (PESSOA, 1976, p. 54)

b) O terror de já não pertencerem a esta vida: "Talvez nada disto seja verdade... Todo este silêncio, e esta morta, e este dia que começa não são talvez senão um sonho... Olha bem para tudo isto... Parece-vos que pertence à vida?..." $\rightarrow 2^{\underline{a}}$ Veladora (PESSOA, 1976, p. 51) "Não sei. Não sei como se é da vida..." $\rightarrow$ 1ํㅡ Veladora (PESSOA, 1976, p. 51).

Donde a necessidade de restabelecerem as fronteiras entre o Real (lá fora) e o Sonho:

a) A necessidade de reparar "só no dia, no dia real, ali fora..." $\rightarrow 1^{\underline{a}}$ Veladora (PESSOA, 1976, p. 51);

b) A necessidade de crer que apenas sonham, de que serão despertadas por alguém que baterá à porta ou irromperá no cômodo: “Quem pudesse gritar para despertarmos!" $\rightarrow 1^{\underline{a}}$ Veladora (PESSOA, 1976, p. 53); "Quando entrar alguém tudo isto acabará... Até lá façamos por crer que todo este horror foi um 
longo sono que fomos dormindo... É dia já... Vai acabar tudo..." $\rightarrow$ 3를 Veladora (PESSOA, 1976, p. 55).

Essa necessidade de restabelecerem as fronteiras entre o Real e o Sonho é ditada pelo lento processo de dissolução, desintegração e perda de identidade que vão sofrendo após o sonho do Marinheiro ter esboroado a fronteira do espaço intervalar em que viviam. Encasteladas no quarto, viviam conscientes de habitam entre Vida/Morte, Tempo/Não tempo, Vigília/Sono, Realidade exterior (o lá fora)/Outra realidade (o sonho).

A aventura do sonho do Marinheiro rompeu as fronteiras. A chegada do dia não traz a certeza de que ainda pertencem a esta vida: dissolvidas com a luz solar, adormecidas - "Com a luz os sonhos adormecem..." $\rightarrow 1^{\text {a }}$ Veladora (PESSOA, 1976, p. 19), já não passam de um sonho do Marinheiro.

A rubrica final funciona como um fiat lux sem o Verbo criador: um galo canta, um carro geme e chia. Só retornarão à vida no momento em que um verbo criador as articular de novo. Ou seja, quando for reatualizado pela leitura ou encenação o drama estático em um quadro do Marinheiro.

\section{8.}

Finda a leitura, estamos às voltas com a recusa do real, com a onipotência da palavra poética capaz de gerar a realidade, com a confusão entre a fantasia e a vida, com a tentativa de imposição da fantasia ao real - em suma, a entronização da palavra poética, da poesia como realidade única e absoluta, ou, a vontade órfica "de substituir a Realidade pela linguagem, ou, se se prefere, a de dar à linguagem uma realidade absoluta" (LOURENÇO, 1955, s/p.).

Dessa perspectiva, o drama O Marinheiro, saído no primeiro número da revista Orpheu, acaba sendo o verdadeiro manifesto do Movimento, na medida em que encarna o encantamento órfico da palavra poética, impondo-a como realidade única e absoluta - espaço inteligível gerador do plano sensível, essa sombra enganosa da verdadeira realidade. Demiurgo platônico, o marinheiro pessoano sonha as sombras de nossa realidade. Enfim, veladoras da realidade, não passamos de meras sombras e reminiscências - simulacros da verdadeira realidade de que nos exilamos.

Ademais, podemos ver no drama estático pessoano a objetificação artística das palavras de Pessoa, inscritas no pórtico da Obra Poética editada no Rio de Janeiro pela Companhia José Aguilar Editora, 1969, p. 15: 
Navegadores antigos tinham uma frase gloriosa: Navegar é preciso, viver não é preciso.

Quero para mim o espírito desta frase, transformada a forma para a casar com o que sou: Viver não é necessário: o que é necessário é criar.

Riobaldo, em Grande Sertão: Veredas, dizia que "viver é muito perigoso". Todavia, O Marinheiro ensina que a aventura interior do sonho é mais perigosa ainda. Dizia a $2^{a}$ Veladora, ao contar o sonho do marinheiro: "Não tentemos seguir nesta aventura interior. Quem sabe o que está no fim dela?"

A reposta deu-a O Marinheiro: no fim da aventura interior do sonho está a desintegração, a dissolução, o desdobramento, a perda do ser e da identidade.

A renúncia à vida para entregar-se à aventura sonambúlica do sonho exige o sacrifício do corpo, da alma, da humanidade individual:

Não conto gozar a minha vida; nem em gozá-la penso. Só quero tornála grande, ainda que para isso tenha de ser o meu corpo e a minha alma a lenha desse fogo.

Só quero torná-la de toda a humanidade; ainda que para isso tenha de a perder como minha. (PESSOA, 1969, p. 15).

\section{REFERÊNCIAS}

LOURENÇO, Eduardo. “Orpheu ou a Poesia como Realidade”. Tetracórnio, fev. 1955.

PESSOA, Fernando. Obra Poética, Rio de Janeiro: Companhia José Aguilar Editora, 1969.

PESSOA, Fernando. “O Marinheiro”. In Orpheu. Lisboa: Ática, 1971.

PESSOA, Fernando. Obras em Prosa. Rio de Janeiro: Nova Aguilar, 1976.

Recebido em 26 de novembro de 2020

Aprovado em 13 de dezembro de 2020

Licença: $($ ) (1) $\circledast$

Francisco Maciel Silveira

Professor Titular Aposentado do Programa de Pós-Graduação em Literatura Portuguesa da Faculdade de Filosofia, Letras e Ciências Humanas da Universidade de São Paulo. Falecido em junho de 2019, sua obra encontra-se sob tutela de sua viúva, Profa. Dra. Flavia Maria Corradin. Contato: corradin@usp.br 